\title{
A microfluidic toolbox for the development of in-situ product removal strategies in biocatalysis
}

Heintz, Søren; Mitic, Aleksandar; Ringborg, Rolf Hoffmeyer; Krühne, Ulrich; Woodley, John; Gernaey, Krist

Published in:

Journal of Flow Chemistry

Link to article, DOI:

$10.1556 / 1846.2015 .00040$

Publication date:

2016

Document Version

Publisher's PDF, also known as Version of record

Link back to DTU Orbit

Citation (APA):

Heintz, S., Mitic, A., Ringborg, R. H., Krühne, U., Woodley, J., \& Gernaey, K. (2016). A microfluidic toolbox for the development of in-situ product removal strategies in biocatalysis. Journal of Flow Chemistry, 6(1), 18-26. https://doi.org/10.1556/1846.2015.00040

\section{General rights}

Copyright and moral rights for the publications made accessible in the public portal are retained by the authors and/or other copyright owners and it is a condition of accessing publications that users recognise and abide by the legal requirements associated with these rights.

- Users may download and print one copy of any publication from the public portal for the purpose of private study or research.

- You may not further distribute the material or use it for any profit-making activity or commercial gain

- You may freely distribute the URL identifying the publication in the public portal 


\title{
A Microfluidic Toolbox for the Development of In-Situ Product Removal Strategies in Biocatalysis
}

\author{
Søren Heintz, Aleksandar Mitic, Rolf H. Ringborg, Ulrich Krühne, John M. Woodley and Krist V. Gernaey* \\ CAPEC-PROCESS Research Center, Department of Chemical and Biochemical Engineering, \\ Technical University of Denmark, Building 229, 2800 Kgs. Lyngby, Denmark
}

Received: 24 October 2015; accepted: 21 December 2015

\begin{abstract}
A microfluidic toolbox for accelerated development of biocatalytic processes has great potential. This is especially the case for the development of advanced biocatalytic process concepts, where reactors and product separation methods are closely linked together to intensify the process performance, e.g., by the use of in-situ product removal (ISPR). This review provides a general overview of currently available tools in a microfluidic toolbox and how this toolbox can be applied to the development of advanced biocatalytic process concepts. Emphasis is placed on describing the possibilities and advantages of the microfluidic toolbox that are difficult to achieve with conventional batch-processbased technologies. Application of this microfluidic toolbox will potentially make it possible to intensify biocatalytic reactions and thereby facilitate the development towards novel and advanced biocatalytic processes, which in many cases have proven too difficult in conventional batch equipment.
\end{abstract}

Keywords: microfluidics, in-situ product removal (ISPR), process intensification, biocatalysis, process development

\section{Introduction}

Today, several hundred industrial processes apply biocatalysis in the production of fine chemicals and pharmaceuticals [1-8]. Furthermore, there is an ever increasing academic and industrial interest in new biocatalytic processes, a development that is driven by the need for selective and efficient organic synthesis [9-12]. Central to the application of biocatalysis for synthetically useful chemistry is that high selectivity and efficiency are realized under mild reaction conditions [11, 13, 14]. However, from nature's perspective, biocatalysts have evolved to efficiently facilitate the conversion of natural substrates under dilute conditions [10]. Consequently, the biggest challenge in the development of new biocatalytic processes, operating at industrially relevant concentrations, is to modify the biocatalyst and the process concept in such a way as to ensure economic feasibility for the conversion of nonnatural substrates $[15,16]$.

The focus in this work is on the development of advanced biocatalytic process concepts, such as in-situ product removal (ISPR) concepts, applying a microfluidic toolbox in the development and testing of such concepts. A microfluidic toolbox consists of currently available microfluidic unit operations, general equipment and software, which will be discussed in more detail in Section 3. The microfluidic toolbox is an obvious available technology for development of ISPR concepts as it enables testing of advanced process concepts that are difficult at best with conventional batch technologies as emphasized in this work. Furthermore, the microfluidic toolbox offers the opportunity to achieve rapid and parallelized testing and, thus, makes it possible to generate the required data to support the process design and development.

It is important to emphasize that it is indeed possible to improve the performance of biocatalysts, e.g., by protein engineering strategies, to operate under industrially relevant reaction conditions [1, 17-19]. However, challenges such as inhibitory and/or toxic effects from products are more difficult to overcome by protein engineering, especially if it has to be overcome in a timely manner [14]. Moreover, challenges such as unfavorable thermodynamics and unstable product(s) cannot be resolved by protein engineering. Hence, many biocatalytic processes will benefit from alternative process concepts, where the biocatalyst is relieved of productrelated limitations by continuously removing the product while

\footnotetext{
* Author for correspondence: kvg@kt.dtu.dk
}

the reaction proceeds. As an example, this can be achieved by linking the biocatalytic reaction with the primary product recovery steps to intensify the process (Figure 1). This linkage is termed insitu product (ISPR) and/or in-situ coproduct removal (IScPR) in the scientific literature (Fact box 1) [20]. Development and testing of such ISPR/IScPR process concepts is challenging with conventional batch-type experiments. In batch-process-based technologies, everything is conceptually combined in a vessel, making it challenging to differentiate the effects of the biocatalyst from effects of the separation and the integration of the two. Furthermore, conventional batch-type experiments are based on extensive manual handling, causing it to be too labor intensive to execute many experiments. This is where a microfluidic toolbox can provide distinct benefits for the development of such processes, because the application of microfluidic modules will make it possible to compartmentalize the different process steps in ISPR/ IScPR strategies during testing. Hence, it will be possible to assess the impact of linking the different process steps and identify the achievable process intensity.

This paper will focus on how a microfluidic toolbox can aid in the development of ISPR concepts for processes based on biocatalysis, to test process concepts that are otherwise difficult to test with conventional batch type experiments. This work is summarizing a relatively narrow application area of the currently available microfluidic toolbox, i.e., development and testing of ISPR concepts in biocatalysis focused on enzymatic catalyzed reactions. However, it is important to emphasize that the concept of combining microfluidic modules for testing process configurations is adaptable to other areas of biocatalysis, e.g., ISPR development for fermentation-based processes. Furthermore, the whole concept of linking and testing multiple process steps in combination is inspired by the advances made in the research area of flow chemistry, where continuous-flow synthesis exploits such combination of microfluidic process steps [21-23].

\section{ISPR in Biocatalysis}

Despite the increasing number of biocatalytic processes applied in industry, there are still many highly relevant biocatalytic processes that are not yet implemented. The main reasons are linked with the commercial need for relatively high product concentrations that influence the biocatalyst significantly and thereby challenge the economic feasibility of the processes [24, 25]. For 


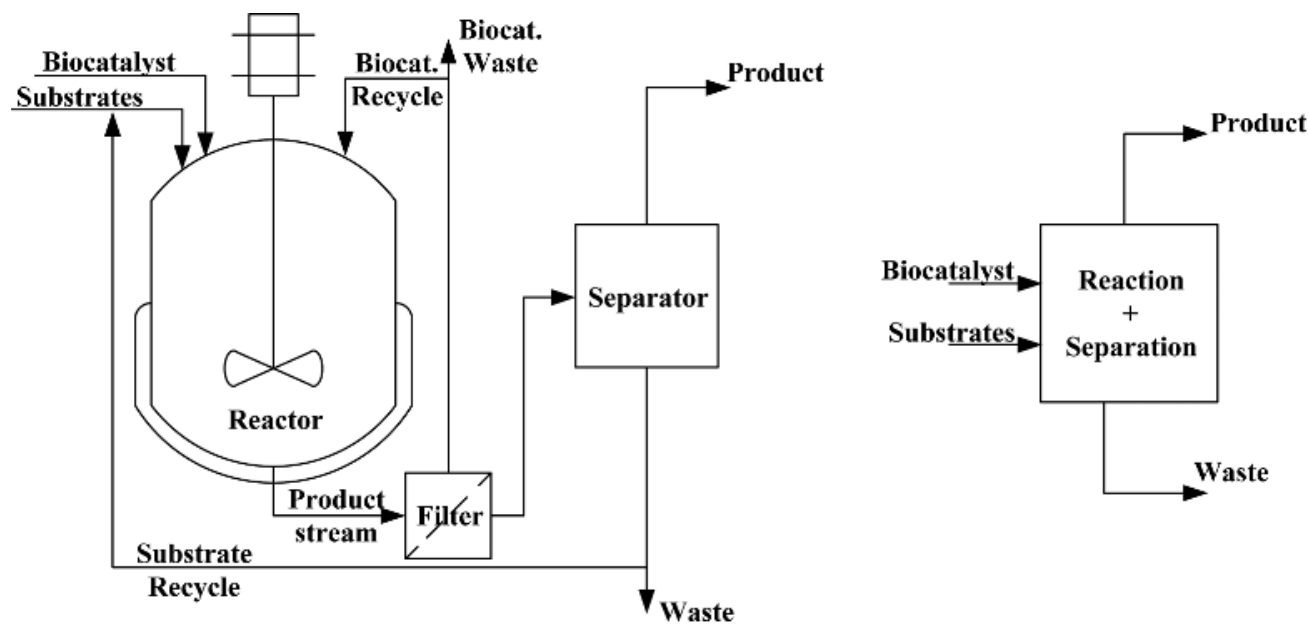

Figure 1. Generalized process flow-sheets of biocatalytic processes exploiting in-situ product removal (ISPR) strategies. Left: This external ISPR strategy links the reactor and the separation units by recycling process streams between the modules/units. Right: This internal ISPR strategy combines the reactor and the separation units in a dedicated module

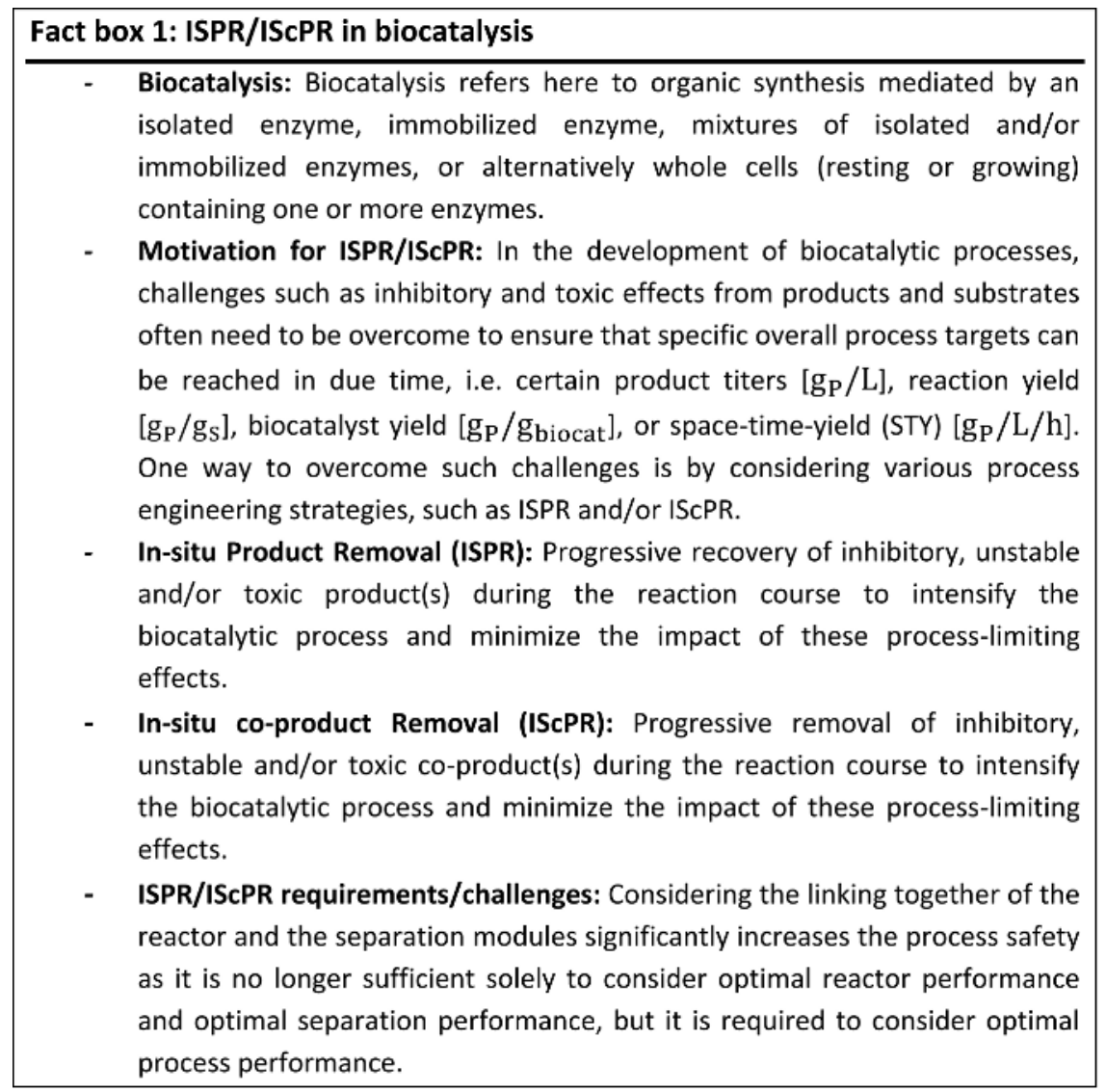

example, increased product titers will cause inhibition, side-reactions, and toxic effects and thereby dictate the efficiency of the process. Hence, implementation of ISPR strategies for such processes, for the continuous removal and concentration of product(s) during operation, will be beneficial as it will minimize those effects and intensify the overall process. The intensification of the overall process is dictated by how efficiently the reaction conditions can be controlled by the ISPR strategy. Important to emphasize is that ISPR implementation will not change the requirements of the overall process to fulfill specific metrics for economic feasibility. For example, it will still be required to reach specific overall process targets exiting the ISPR configuration, such as certain product titers $\left(g_{P} / L\right)$, reaction yield $(\%)$, biocatalyst yield $\left(g_{P} / g_{\text {biocat }}\right)$, or space-time yields (STY) $\left(g_{P} / L / h\right)$ [26]. High product titers exiting the ISPR configuration are important in terms of how costly the following DSP will be. In cases where IScPR is implemented, then the outlet stream containing the coproduct does not necessarily need to have a high titer, as it only sometimes will be required to recover the coproduct.

2.1. ISPR Separation Strategies. The choice of ISPR separation strategy is commonly based upon exploiting differences in the physicochemical properties of the involved reaction species [26]. Thus, one approach is to exploit conventional separation principles as ISPR/IScPR strategies, which is closely linked to the DSP. The interest in this article is to apply microfluidic modules in order to link reaction and downstream processing steps in biocatalytic processes. Another approach is to perform the separation based upon cascade reactions [27-29], 
i.e., the ISPR/IScPR strategy is dependent on multiple reactions that are performed simultaneously, which is outside the scope of this article.

Some of the most commonly exploited physicochemical differences in DSP and ISPR strategies, based on conventional separation principles, are listed in Table 1 [24, 25, 30, 31]. Also indicated in the table are commonly applied unit operations that exploit these indicated differences in physicochemical properties as separation principle. The listed unit operations give a good indication of different microfluidic separation modules that are required in a microfluidic toolbox to quickly assess and test various ISPR options. In terms of separating and recycling of the biocatalyst, if required, size differences are often exploited, i.e., filtration or membrane-based separation [32, 33]. There are of course also more complex examples where a combination of several differences in physicochemical properties is exploited to separate compounds from complex reaction mixtures [34]. These differences are case dependent, which makes the choice and options of suitable ISPR strategies case specific. Furthermore, any microfluidic toolbox needs to provide similar flexibility as batch-process-based technologies. Batch-process-based technologies offer the advantage of being flexible, making it easy to perform simple ISPR relevant screening and characterization experiments. In addition, when applying technologies such as well plates, a relatively high throughput can be achieved [35]. It is therefore essential that any microfluidic toolbox is flexible, enables easy testing and high throughput of different DSP and ISPR options to be competitive. However, an additional advantage of applying a microfluidic toolbox for such testing is that the reaction and separation steps can be compartmentalized in the testing. In many cases, this is not possible in batch-process-based technologies, where all is combined in a single vessel.

In Table 2, examples are presented of different biocatalytic applications where ISPR is considered as a means to overcome the apparent product-related challenges. It is pointed out in the table how the implementation of various ISPR strategies in relation to the different examples benefits the overall processes. Even though the examples solely focus on enzyme-catalysis-based applications in relation to the pharmaceutical industry, the ISPR strategies are also highly relevant to other biocatalytic applications [30], e.g., in many fermentation-based processes [25, 34, 36]. Hence, the examples demonstrate the current and future value of ISPR technologies, in an era with increasing focus on implementing biocatalysis in the fine chemical and pharmaceutical industries.

2.2. Challenges. Although there are many examples of biocatalytic processes considering ISPR strategies, based on conventional separation principles at a laboratory scale, it is not common that such strategies are implemented at industrial scale. This is to some extent caused by increased process complexity when adding on an ISPR strategy, which (often) makes it challenging to justify industrial scale implementation $[24,25]$. Hence, the major challenge for increased industrial implementation of ISPR process concepts is ensuring in-depth understanding of the overall gain, in terms of process intensification and economic feasibility, from such implementation [25]. Furthermore, it is important that ISPR strategies enable long term robustness and stability [25]. Therefore,

Table 1. Examples of commonly exploited differences in physicochemical properties (driving forces) for ISPR applications and related unit operations Separation principle Unit operations

\begin{tabular}{|c|c|c|}
\hline Volatility & $\Delta k_{\mathrm{H}}$ & $\begin{array}{l}\text { Pervaporation, gas stripping, } \\
\text { distillation }\end{array}$ \\
\hline Charge & $\Delta \log \mathrm{p} K_{\mathrm{a}}$ & $\begin{array}{l}\text { Adsorption, extraction, } \\
\text { membrane, crystallization, } \\
\text { ion exchange, dialysis }\end{array}$ \\
\hline Solubility & $\Delta C_{\mathrm{sol}}^{\circ}\left(\Delta K_{\mathrm{c}}\right)$ & Extraction, crystallization \\
\hline Hydrophobicity & $\Delta \log P$ & Membrane, extraction \\
\hline
\end{tabular}

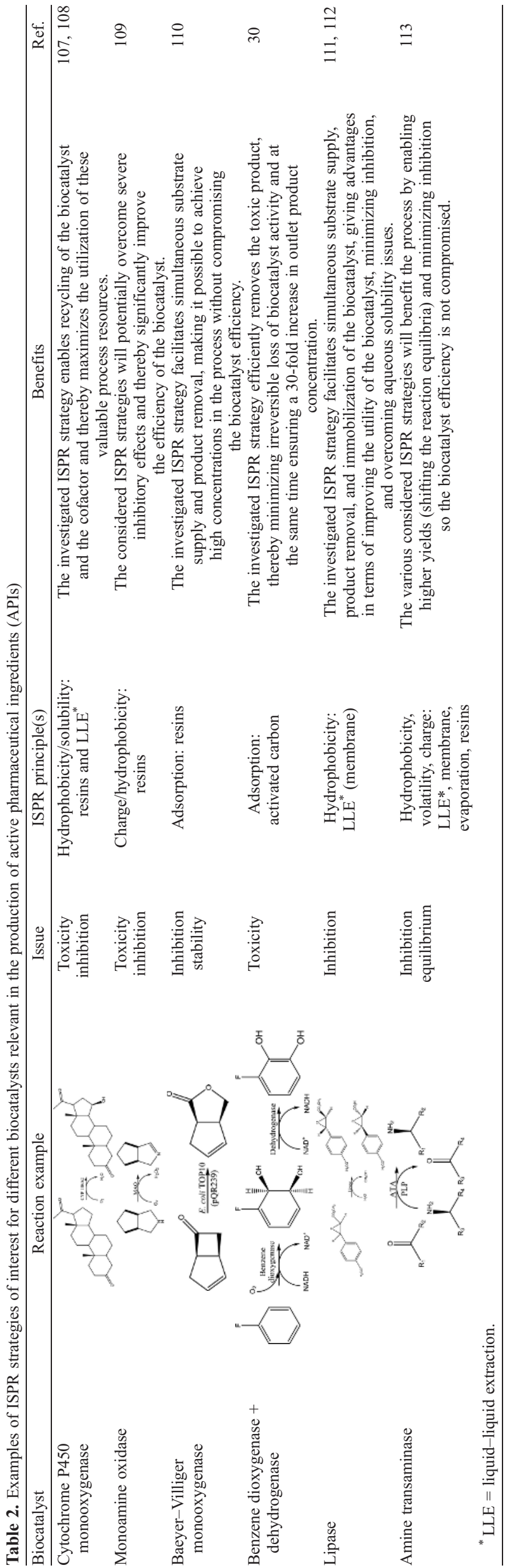


the identification, development, and optimization of the most suitable ISPR strategy require extensive testing. For example, it is required to characterize the biocatalytic reactor and separation steps, while at the same time evaluating how these steps can be linked together in an optimal manner. All these elements need to be investigated in detail in order to make reliable predictions of the impact of implementing ISPR strategies and if pursuing such process strategies can be economically justified [30]. Such in-depth knowledge will also allow identifying the limitations of various ISPR strategies. Common limitations of different ISPR strategies can be related to the selectivity, kinetics, capacity, and compatibility (in relation to the biocatalyst and operational conditions). Hence, applying state of the art technologies, such as a microfluidic toolbox, that enable rapid characterization, will assist the development of such processes and potentially make it easier and faster to develop new biocatalytic processes. Therefore, we suggest that a microfluidic toolbox could be a good technology to help extensive investigations and developing ISPR process concepts, which will enable the required in-depth understanding of this complexity. Thus, it will facilitate reliable predictions of the process performance and overall gain from the implementation. Additionally, this in-depth understanding will enable better economic assessment of such process concepts.

\section{A Microfluidic Toolbox for ISPR Development}

Microfluidic devices have found widespread applications in the area of organic synthesis, for development of novel synthesis methods and routes $[37,38]$. In some cases, they have also been used for actual manufacturing of fine chemicals and pharmaceuticals $[37,39,40]$. The aim here is to highlight how that knowledge can be transferred and applied to the development of intensified biocatalytic processes exploiting ISPR concepts and principles.

3.1. A Microfluidic Toolbox. The research area of microfluidics has developed tremendously in recent years, and the technology is today relatively mature [37]. Consequently, a large number of microfluidic modules with dedicated functions and features have become readily available covering a multitude of applications, i.e., a microfluidic toolbox. The microfluidic toolbox consists of commercially available and custom-made microfluidic tubes, modules, and/ or chips applicable for facilitating, for example reactions, mixing, and separations [21, 41]. Moreover, specific modules for detection of the concentration of compounds of interest can also be inserted directly in the microfluidic process configuration.

The development of microfluidic separation modules is of great importance when considering applying the microfluidic toolbox for development of ISPR strategies in biocatalysis. Furthermore, it is a tremendous advantage to apply user-friendly computational fluid dynamics (CFD) software tools, which perform well under laminar flow conditions, in combination with microfluidics. In particular, such software tools are combined with kinetic models for the microfluidic reactors and/or separation modules, which leads to virtual experimentation and the possibility to optimize the configuration of the microfluidic modules [42]. Examples of elements in the microfluidic toolbox of high relevance for biocatalytic process development cover the following:

- Standard equipment: A key element in the microfluidic toolbox is the standard equipment surrounding the microfluidic modules, i.e., tubing, pumps, connectors, mixers, valves, pressure regulators, etc. [22, 37, 43, 44]. Many different options are commercially available for each of these types of equipment, which is a clear advantage. For example, it is possible to purchase various valves, connectors, and tubes in different dimensions and materials, e.g., polymers, glass, and/or metals [22, 43]. In many cases, one operates microfluidic systems with syringe pumps, but it is also possible to apply microfluidic piston pumps, gear pumps, membrane pumps, and peristaltic pumps [43]. Hence, the microfluidic toolbox requires a small investment in such standard equipment unless a customized solution is required/developed.

- Reactors: In terms of microfluidic biocatalytic reactors, a vast number of options have been tested and developed, which have been reviewed by Bolivar and Nidetzky [45] and by Wohlgemuth and coworkers [20]. For example, it is possible to operate tube- and/or chip-based reactors with biocatalysts free in suspension as either free enzyme [46, 47], crude cell lysate [20,48], or whole cells [49]. Alternatively, different immobilization forms, such as entrapment in porous particles, cross-linked enzyme aggregates (CLEAs) [45], and immobilization on solid particles [49-52] and on the reactor surface [53], can be applied in tubes, chips, and/or packed-bed reactors. Thereby, microfluidic reactors have proven to be highly versatile in terms of testing numerous biocatalytic application forms.

It is important to point out that the continuous-flow nature of microfluidics makes this technology suitable for development of continuous process concepts $[38,54,55]$. Continuous processes are recognized to give benefits such as reduced down-times, increased space-time yields, steadystate operation, improved heat, and mass transfer control, to name a few [56-58]. However, not all processes are suited to be operated in continuous modes [21]. Therefore, it is important to emphasize that application of microfluidic reactors for process development is not restricted to continuous applications [59], which again demonstrates the versatility of the microfluidic toolbox.

In terms of developing ISPR process strategies, then this flexibility of operating the microfluidic biocatalytic reactors in various operating modes and with various biocatalyst formulations is valuable. For example, it gives the possibility to test different ISPR operating modes such as deciding if the biocatalyst should be operated with or without direct contact with the separation step(s). Furthermore, this flexibility gives a unique benefit in terms of being able to quickly switch between testing various formulation options and how the formulation impacts the choice of ISPR strategies.

- Separators: Application of micro- and mesoscale devices for downstream processing also forms a very useful element in the toolbox. The main advantages are associated with the easy integration of such processes in the overall process architecture, which leads to the minimization of potentially wasted time, reagents, and equipment. ISPR in biotechnological applications can therefore be tested more rapidly and thoroughly. The separation modules are commonly based on the fundamental principles in separations, i.e., differences in volatility, charge, solubility, or hydrophobicity, which are all important for testing ISPR concepts as pointed out in Section 2.1.

- Volatility: Volatility is a very applicable phenomenon in the microscale. It has been widely used for analytical and preparative separations of mixtures in continuous mode [60]. Examples can be found in the food industry, such as a highly selective on-line volatilization for continuous removal of $\mathrm{SO}_{2}$ from wine [61], rapid determination of fluoride [62], or rapidly increasing concentration of electrolytes [63]. Moreover, successful separation of two miscible liquids was performed by Wootton and coworkers 
[64], who managed to perform evaporation at temperatures that are even below the boiling points of the tested solvents. Assistance of membranes could additionally improve selectivity [65] and enable continuity in multistep processes [66]. Plenty of relevant applications have also been summarized by Hartman and coworkers [67], who emphasized the advantages of the application of such small devices at the microscale level. In addition, Salmon and coworkers [68] report the simplicity of mathematical modeling when such devices are considered. Focusing on biotechnological applications, it is important to note that Cooney and coworkers [69] performed rapid determination of stereo-specificity in the analysis of inosine monophosphate (IMP) dehydrogenase. In terms of developing ISPR strategies, then these various microfluidic modules can be applied to test ISPR options that are based on differences in volatility. For example, in Table 2, it is pointed out that amine transaminases can benefit from ISPR options based on differences in volatility. Therefore, in such cases, it will be highly relevant to apply microfluidic modules to test stripping and/or pervaporationbased ISPR options for the continuous removal of volatile compounds.

- Charge: Charge is a phenomenon that is widely applicable in biotechnological applications. For example, electrophoresis is often applied for screening procedures of enzyme inhibitors [70] or for achieving separation of proteins [71]. Advantages of using such devices for electrophoresis are linked to easier automation of processes, which leads to a high degree of process integration in biological systems [72]. Excellent reviews by Giles and coworkers [73], Khandurina and coworkers [74], Figeys and coworkers [75], and Guihen [76] have documented the developments in this area. Furthermore, it is possible to test ion exchange and dialysis methods in microfluidic modules, which are especially important when considering potential ISPR options for biocatalytic processes. For example, in Table 2, examples were given where monoamine oxidases and amine transaminases could benefit from ISPR strategies based on charge differences.

- Solubility: Very reliable extraction processes could be performed by applying such phenomena in microscale devices. For instance, Robins and coworkers [77] managed to effectively extract $\mathrm{Fe}^{\mathrm{III}}$ between aqueous and water phases whereas Kirschneck and coworkers [78] performed rapid transfer of acetone between water and hexane. A combination of different extraction modules could also be applied and was reported by Li and coworkers [79], who combined dispersive liquid-liquid microextraction with single drop microextraction for fast determination of chlorophenols. In this way, a highspeed, simple, and efficient method was achieved for sample preparation. Focusing on biotechnological applications, Ekström and coworkers [80] successfully tested extraction at the microscale for purification and increasing concentrations of sample solutions as a preparation for matrix-assisted laser desorption ionization time-offlight mass spectrometry (MALDI-TOF MS). A range of microextraction applications was also summarized by Yan and coworkers [81]. Such microfluidic modules are important elements in testing ISPR strategies as well. For example, most of the examples highlighted in Table 2 are considering liquid-liquid extraction. Furthermore, differences in solubility can be applied to test ISPR strategies based on crystallization, which could be highly relevant for development of some ISPR strategies for fermentations [36].
- Hydrophobicity: The last phenomenon considered here is hydrophobicity. Differences in hydrophobicity are useful for liquid-liquid separations and solid-phase extractions. Focusing on liquid-liquid separations, a very rapid, simple, and robust method could be developed for separating two immiscible liquids. CerveraPadrell and coworkers [82] performed successful separation of toluene and water by applying a suitable PTFE membrane at microscale. Li and coworkers [83] designed a more sophisticated setup that continuously recycled homogeneous palladium catalyst by applying liquid-liquid phase separation and permeable membranes. In this way, a continuous process could be established with a higher interface area/volume ratio and reduced diffusion distances compared to conventional processes [84, 85]. Likewise, solid-phase extraction operations are frequently applied in biotechnological processes. For instance, Bechtold and coworkers [86] avoided thermodynamic limitations by establishing insitu product removal whereas Shieh and coworkers [87] performed successful selective separation of products in the hydrolysis of lactose by Aspergillus oryzae. The selective permeability of membranes was applied here as well such as in- and ex-situ product removal in the Knoevenagel condensation reaction [88], where a Pdmembrane was used for catalytic dehydrogenation of cyclohexane [89]. For the development of ISPR strategies, then differences in hydrophobicity can be applied to put in place phase separation modules, giving some beneficial features for the development of ISPR strategies based on continuous liquid-liquid extraction (LLE). Furthermore, it also gives testing possibilities in terms of testing extraction with hydrophobic resins as another example.

The microfluidic toolbox has the advantage that a combination of separation technologies in microscale devices can also be applied relatively straightforwardly, i.e., giving high flexibility for testing ISPR options. Du and coworkers [90] combined solid-phase extraction, distillation and extraction in order to prepare samples for GC-MS. A detailed review about different microseparation approaches of fluid systems was made by Kenig and coworkers [91]. The strength of having various microfluidic modules operated in combination as individual modules is that it provides high flexibility to quickly modify and change the different process steps. For example, it makes it easy to change the dimensions of the separation relative to the reactor and/or replace the reactor/separation modules when testing different ISPR concepts for different processes, which will be discussed further in Sections 3.2 and 3.3.

- Detectors: An important development in the microfluidic toolbox is the possibility to implement a large number of different detection methods to monitor the progress of microfluidic systems. For example, many standard analytical methods, such as fluorescent measurements, UV spectroscopy, IR spectroscopy, Raman spectroscopy, NMR, HPLC and MS have successfully been implemented with microfluidic systems [92]. Figure 2 shows an example of a custom-made microfluidic chip with integrated biosensor spots based on fluorescence. Implementation of in-line and on-line detection methods is important in microfluidic systems since it facilitates detection with small sample volumes, increased experimental throughput, and reduces manual labor, i.e., no manual sampling and work-up is required [92]. Additionally, it is important to have 


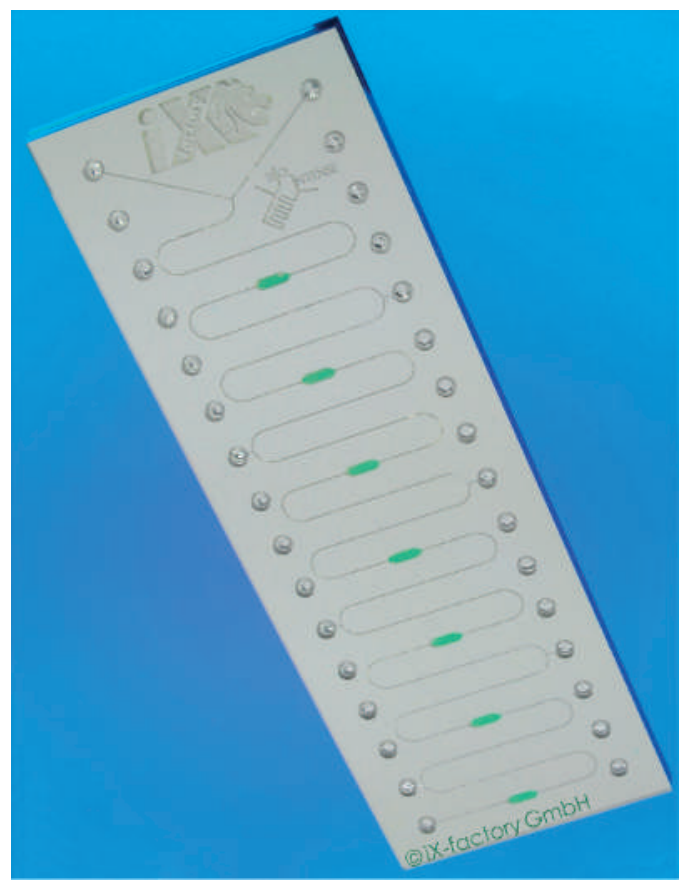

Figure 2. Microfluidic meander structured chip with integrated biosensors (green dots) for optical monitoring of reaction progress. The chip was developed and manufactured by iX-factory $\mathrm{GmbH}$, Dortmund, Germany. Shown with permission from iX-Factory GmbH

microscale experiments with dynamic data, i.e., on-line/inline data and not end point measurements, which is often the case with batch experiments. Furthermore, on-line/in-line measurement methods will open up for the possibility to have fully automated experimental setups in terms of data acquisition and interpretation [92]. Integration of sensors is especially important when testing complex process concepts such as ISPR strategies in biocatalysis, as it will enable high-resolution data and minimize disruptions caused by manual sampling. Furthermore, it should be emphasized that the application of soft sensors to predict additional variables of interest enables the use of mechanistic models and parameter estimation on the data in order to validate the models and the experimental setup [93].

3.2. Advantages of a Microfluidic Toolbox. There are numerous benefits and key features associated with the application of microfluidic modules [37, 45, 92, 94-98]. Some of these benefits and features are essential for the development and testing of ISPR/IScPR process concepts in an easy, fast and reliable manner (Fact box 2).

Easy combination of different modules makes the microfluidic toolbox highly flexible for testing various combinations of reactors and separation modules [52, 99]. Additionally, this flexibility allows the user to investigate numerous process options and concepts in detail, using only small quantities of the available resources. The low resource consumption per experiment is a clear advantage, as it can be costly to produce the small quantities of biocatalyst required for screening purposes. Furthermore, combining microfluidic modules enables separate operation of the reactor and separation, and to link them simply by introducing recycling streams between the modules (see Figure 1). The modules can also be combined into dedicated single modules if required, i.e., lab-ona-chip concept [100].

Another important feature of a microfluidic toolbox is the automated interface, e.g., pressure driven pumps control liquid flow in the modules [100], which reduces manual labor during experiments. Implementation of on-line and/or in-line monitoring will furthermore make it possible to operate the microfluidic modules fully automatic [92], i.e., no/minimal manual sample handling is required during experiments. This will ultimately result in high throughput testing and improved reproducibility along with developing detailed knowledge of the tested process concepts [94].

\begin{tabular}{l} 
Fact box 2: A microfluidic toolbox for ISPR/IScPR development \\
\hline - \\
microfluidics: The control and manipulation of fluids in channels with \\
Microfluidic toolbox: Commercially available and custom-made microfluidic \\
modules and/or chips applicable for facilitating for example reactions, \\
mixing, detection and/or separations. \\
- Flexibility (Plug-and-play): The different modules in a microfluidic toolbox \\
make it easy to combine reactor and separation modules, as desired, to test \\
ISPR/IScPR concepts that are difficult to test in conventional batch systems. \\
Furthermore, this can be a good preliminary approach before designing and \\
fabricating dedicated modules/chips for extensive testing, if required. \\
Sample handling: Automated control and operation of microfluidic modules \\
individually or in combination increases reproducibility, minimizes manual \\
labor and deviations caused by sample handling. \\
High surface-to-volume ratio: This feature along with the short diffusion \\
distances in microfluidic channels facilitates fast mass transfer, resulting in \\
quick separation of the (co-)product, i.e. equilibrium is reached fast for two- \\
phase systems. Furthermore, this feature makes it possible to have efficient \\
temperature control in microfluidic modules. \\
Resource consumption: The small internal volume in microfluidic modules \\
results in low consumption of scarce and valuable resources in the initial \\
process development phase. Furthermore, the low consumption of resources \\
per experiment makes it possible to perform extensive investigations, with \\
the available resources, compared to conventional lab scale experiments.
\end{tabular}


The large surface-to-volume ratio and small characteristic length scales in microfluidic channels enable fast mass transfer, which is important for ISPR/IScPR applications [20]. The fast mass transfer in microfluidics allows equilibrium to be reached in a short time. Hence, this ensures fast removal of unstable, inhibitory and/or toxic products, and thereby minimizes product losses and reduced biocatalyst performance.

3.3. Plug-and-Play Microfluidics. The concept of combining microfluidic modules to test promising and novel process concepts is one of the key benefits of a microfluidic toolbox and can be referred to as plug-and-play microfluidics [20]. The concept of applying microfluidic modules in a plug-and-play manner for testing multi-step processes is not new, and creating a framework for such modularization has been emphasized a number of times in the past [98, 99, 101-103]. However, applications of microfluidic modules in a plug-and-play manner for biocatalytic applications to date have only been attempted a few times [46, 104, 105]. The plug-and-play concept allows to test and characterize the required microfluidic modules for a specific application both individually and in combination [104]. Furthermore, generic solutions can be integrated into a single chip solution (see Figure 3). Figure 4 provides an example of a commercially available plug-and-play microfluidic test platform.

There are several benefits of applying the microfluidic plugand-play concept for testing ISPR/IScPR options in biocatalysis compared to conventional batch testing. For example, this gives a distinct advantage compared to batch operation for ISPR testing, as it is possible to integrate multiple separation steps and reactors in a variety of ways, i.e., compartmentalization of the different process steps. In batch operations, the integration is done in a single vessel, making it challenging to compartmentalize the different steps and thereby difficult to get in-depth understanding of the limitations of the tested processes. Furthermore, compartmentalizing the different process steps is not only valuable for testing ISPR concepts but also important for processes that do not require an ISPR concept. For example, the precise control of fluids in microfluidic systems gives an

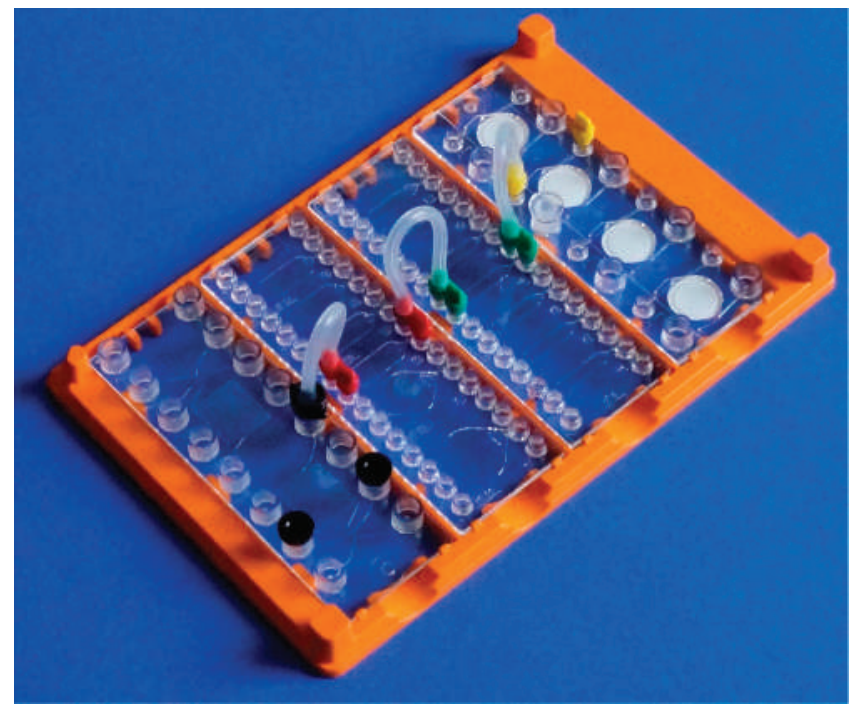

Figure 4. Commercially available microfluidic modular test platform (plug-and-play). Shown with permission from microfluidic ChipShop $\mathrm{GmbH}$

advantage compared to batch testing as it is easier to separate the reaction from the separation and vice versa. Furthermore, such control makes it possible to regenerate/replace the separation material/solution during operation in an easy and potentially automated manner compared to batch.

\section{Reservoirs for Microfluidic Recycling}

A challenge in the implementation and testing of ISPR options applying microfluidic modules in combination is the recycling of streams. A simple solution is to recycle streams using reservoirs, where the applied pumps can pump from/to during operation (see Figure 3). However, the application of reservoirs will significantly increase the required volume for
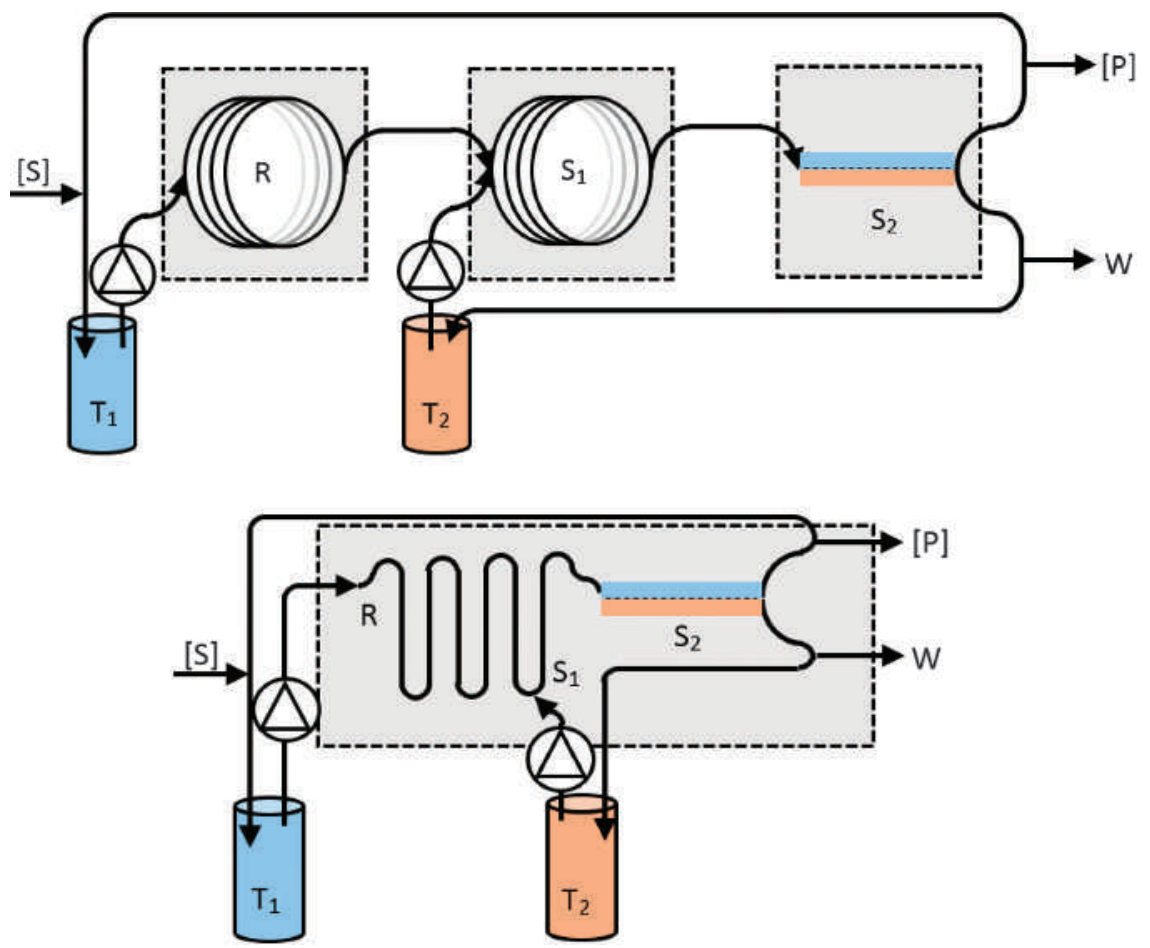

Figure 3. Illustration of the plug-and-play concept of microfluidic modules for testing ISPR strategies in biocatalysis (top) and the dedicated on-chip ISPR concept (bottom). $T_{1}$ and $T_{2}$ are fluid reservoirs. R corresponds to a reactor module. $S_{1}$ and $S_{2}$ correspond to a separator and splitter, respectively. $[\mathrm{S}]$ represents substrate feeding, while $[\mathrm{P}]$ and $\mathrm{W}$ represent product and waste streams, respectively 
testing, as some pumps require a certain volume in the reservoir to operate. For example, automatically operated syringe pumps will remove a volume corresponding to the applied syringe volume every time the pump refills. Hence, the reservoir needs a certain volume not to empty, draw in air, or cause vacuum. Furthermore, increasing reservoir volume will increase the ISPR system response times and thereby affect the experimental volume and throughput. Especially, the increased response times can be an issue, as it will require the system to operate with excessive recycles relative to the throughput to test the impact of removing product(s) during the reaction course efficiently. Despite the obvious drawback of large reservoir volumes, e.g., $1 \mathrm{~mL}$, then it is difficult to avoid reservoirs in the ISPR process development phase, where it is required to have flexibility to rapidly modify process configurations to find the most feasible options. This flexibility can be maintained by combining the microfluidic modules through recycling from reservoirs.

On the other hand, when suitable ISPR options are identified, it is possible to design dedicated microfluidic chips, where the reaction and separation steps are directly linked and thereby the need for reservoirs can potentially be avoided if no streams need to be recycled. Additionally, with dedicated chips, it is possible to integrate the reaction and separation steps completely, which is essential in cases where excessive recycling is required to be efficient. Dedicated solutions in many cases will be the aim after initial plug-and-play testing, for extensive testing of the system, e.g., in cases where the most feasible solution has been identified from test systems with larger reservoirs. Also, dedicated solutions are required when fully integrated ISPR solutions are required, as it is the only way to ensure sufficient separation response times relative to the reaction course. Furthermore, the direct linkage of the reaction and separation makes it possible to operate the system in countercurrent mode, which can be beneficial for various applications [23, 103, 106]. However, if the applied separation method is not highly selective, it will cause significant substrate losses during operation in the dedicated solutions, i.e., due to simultaneous substrate removal. If the solubility of the substrate is low in the reaction phase, it can be beneficial to consider substrate feeding strategies from the applied separation phase. However, such applications will potentially require streams to be recycled to ensure high enough yield in the reaction. Another challenge of the dedicated solution is that it is still required to perform individual tests of the different modules in the considered ISPR strategy. Testing of the individual modules is required to identify the performance of each step and apply this knowledge to develop reliable models needed to identify the achievable gain of different potentially feasible ISPR strategies.

\section{Conclusion and Future Outlook}

Benefits of applying a currently available microfluidic toolbox for the development of advanced and intensified biocatalytic processes exploiting in-situ product removal (ISPR) strategies have been identified. The toolbox ultimately makes it possible to support the development of novel and efficient biocatalytic processes, which are operationally and economically challenged in conventional batch type processes. Additionally, it was emphasized that a microfluidic toolbox will make it possible to consider advanced biocatalytic process concepts that are otherwise difficult to test and operate with conventional batch-based concepts. Microfluidics is a relatively mature technology, and thereby the currently available microfluidic toolbox provides considerable flexibility to test different reactor types and separation methods in combination in an easy manner. Furthermore, the low resource consumption required to perform experiments, in combination with the automated microfluidic interface, facilitates extensive and fast testing and thereby increases process knowledge. This extended knowledge base is essential for setting targets for the further development of the process and biocatalyst to reach economic feasibility requirements. Thereby, besides supporting the development of novel and advanced biocatalytic processes, the currently available microfluidic toolbox also has the potential to accelerate the process development.

Acknowledgement. The authors would like to acknowledge the European Union Seventh Framework Programme (FP7/20072013) for funding part of this work through the BIOINTENSE project, grant agreement no. 312148. In addition, the authors would like to acknowledge the Technical University of Denmark (DTU) for cofunding the work. Finally, the Novo Nordisk Foundation is acknowledged for funding the work in the frame of the project "Exploring biochemical process performance limits through topology optimization."

\section{References}

1. Bornscheuer, U. T.; Huisman, G. W.; Kazlauskas, R. J.; Lutz, S.; Moore, J. C. Robins, K. Nature 2012, 485, 185-194.

2. Schmid, A.; Dordick, J. S.; Hauer, B.; Kiener, A.; Wubbolts, M.; Witholt, B. Nature 2001, 409, 258-268.

3. Schmid, A.; Hollmann, F.; Park, J. B.; Bühler, B. Curr. Opin. Biotechnol. $\mathbf{2 0 0 2}, 13,359-366$

4. Straathof, A. J.; Panke, S.; Schmid, A. Curr. Opin. Biotechnol. 2002, 13, $548-556$

5. Van Beilen, J. B.; Li, Z. Curr. Opin. Biotechnol. 2002, 13, 338-344.

6. Kirk, O.; Borchert, T. V.; Fuglsang, C. C. Curr. Opin. Biotechnol. 2002, 13, 345-351.

7. Choi, J.-M.; Han, S.-S.; Kim, H.-S. Biotechnol. Adv. 2015, 33, 1443-1454. 8. Wells, A. S.; Finch, G. L.; Michels, P. C.; Wong, J. W. Org. Process Res. Dev. 2012, 16, 1986-1993.

9. Pollard, D. J.; Woodley, J. M. Trends Biotechnol. 2007, 25, 66-73.

10. Nestl, B. M.; Nebel, B. A.; Hauer, B. Curr. Opin. Chem. Biol. 2011, 15, 187-193.

11. Schulz, S.; Girhard, M.; Urlacher, V. B. ChemCatChem 2012, 4, 1889-1895 12. Ghislieri, D.; Turner, N. J. Top Catal. 2014, 57, 284-300.

13. Turner, N. J.; O'Reilly, E. Nat. Chem. Biol. 2013, 9, 285-288.

14. Höhne, M.; Bornscheuer, U. T. ChemCatChem 2009, 1, 42-51.

15. Krühne, U.; Heintz, S.; Ringborg, R.; Rosinha, I. P.; Tufvesson, P.;

Gernaey, K. V.; Woodley, J. M. Green Process Synth. 2014, 3, 23-31.

16. Zheng, G. W.; Xu, J. H. Curr. Opin. Biotechnol. 2011, 22, 784-792.

17. Turner, N. J. Nat. Chem. Biol. 2009, 5, 567-573.

18. Höhne, M.; Bornscheuer, U. T. Angew. Chem., Int. Ed. 2014, 53, 1200-1202.

19. Fesko, K.; Gruber-Khadjawi, M. Chem CatChem 2013, 5, 1248-1272.

20. Wohlgemuth, R.; Plazl, I.; Žnidaršič-Plazl, P.; Gernaey, K. V.; Woodley, J. M.

Trends Biotechnol. 2015, 33, 302-314.

21. Malet-Sanz, L.; Susanne, F. J. Med. Chem. 2012, 55, 4062-4098

22. Hartman, R. L.; Jensen, K. F. Lab Chip 2009, 9, 2495-2507.

23. Aota, A.; Mawatari, K.; Kitamori, T. Lab Chip 2009, 9, 2470-2476.

24. Bechtold, M.; Panke, S. Chim. Int. J. Chem. 2009, 63, 345-348.

25. Van Hecke, W.; Kaur, G.; De Wever, H. Biotechnol. Adv. 2014, 32, $1245-1255$.

26. Tufvesson, P.; Lima-Ramos, J.; Haque, N. Al; Gernaey, K. V.; Woodley, J. M. Org. Process Res. Dev. 2013, 17, 1233-1238.

27. Simon, R. C.; Richter, N.; Busto, E.; Kroutil, W. ACS Catal. 2014, 4, $129-143$

28. Tauber, K.; Fuchs, M.; Sattler, J. H.; Pitzer, J.; Pressnitz, D.; Koszelewski, D.; Faber, K.; Pfeffer, J.; Haas, T.; Kroutil, W. Chem. - Eur. J. 2013, 19, 4030-4035. 29. Schrittwieser, J. H.; Sattler, J.; Resch, V.; Mutti, F. G.; Kroutil, W. Curr. Opin. Chem. Biol. 2011, 15, 249-256.

30. Lye, G. J.; Woodley, J. M. Trends Biotechnol. 1999, 17, 395-402.

31. Freeman, A.; Woodley, J. M.; Lilly, M. Biotechnology 1993, 11, 1007-1012.

32. Liese, A.; Hilterhaus, L. Chem. Soc. Rev. 2013, 42, 6236-6249.

33. Eș, I.; Vieira, J. D. G.; Amaral, A. C. Appl. Microbiol. Biotechnol. 2015,

99, 2065-2082

34. Stark, D.; von Stockar, U. Adv. Biochem. Eng. Biotechnol. 2003, 80, 149-175. 35. Halim, M.; Rios-Solis, L.; Micheletti, M.; Ward, J. M.; Lye, G. J. Bioprocess

Biosyst. Eng. 2014, 37, 931-941.

36. Urbanus, J.; Roelands, C. P. M.; Verdoes, D.; ter Horst. J. H. Chem. Eng. Sci. 2012, 77, 18-25.

37. Elvira, K. S.; Casadevall i Solvas, X.; Wootton, R. C. R.; de Mello, A. J. Nat. Chem. 2013, 5, 905-915.

38. Roberge, D. M.; Zimmermannm B.; Rainone, F.; Gottsponer, M.; Eyholzer, M.; Kockmann, N. Org. Process Res. Dev. 2008, 12, 905-910.

39. Roberge, D. M.; Gottsponer, M.; Eyholzer, M.; Kockmann, N. Chim Oggi. 2009, 27, 8-11.

40. Baraldi, P. T.; Hessel, V. Green Process Synth. 2012, 1, 149-167.

41. Gärtner, C.; Becker, H.; Anton, B.; Rötting, O. Proc. SPIE 2004, 5345, 
42. Pereira Rosinha, I.; Gernaey, K. V.; Woodley, J. M.; Krühne, U. In Proceedings of the 25th European Symposium on Computer Aided Process Engineering; 2015; Vol. 37, pp. 1465-1468.

43. Darvas, F.; Dormán, G.; Hessel, V. Flow Chemistry, 1st ed.; Berlin,

Boston: Walter de Gruyter, 2014.

44. Hessel, V.; Löwe, H. Chem. Eng. Technol. 2003, 26, 13-24.

45. Bolivar, J. M.; Nidetzky, B. Green Process. Synth. 2013, 2, 541-559.

46. Novak, U.; Znidarsic-Plazl, P. Green Process. Synth. 2013, 2, 561-568.

47. Pohar, A.; Žnidaršič-Plazl, P.; Plazl, I. Chemical Eng. J. 2012, 189-190,

376-382.

48. Lawrence, J.; O'Sullivan, B.; Lye, G. J.; Wohlgemuth, R.; Szita, N. J.

Mol. Catal. B, Enzym. 2013, 95, 111-117.

49. Andrade, L. H.; Kroutil, W.; Jamison, T. F. Org. Lett. 2014, 16, 6092-6095. 50. Babich, L.; Hartog, A. F.; Van Hemert, L. J. C.; Rutjes, F. P. J. T.; Wever, R. ChemSusChem 2012, 5, 2348-2353.

51. Denčić, I.; De Vaan, S.; Noël, T.; Meuldijk, J.; De Croon, M.; Hessel, V. Ind. Eng. Chem. Res. 2013, 52, 10951-10960.

52. Tamborini, L.; Romano, D.; Pinto, A.; Bertolani, A.; Molinari, F.; Conti, P.

J. Mol. Catal. B, Enzym. 2012, 84, 78-82.

53. Thomsen, M. S.; Nidetzky, B. Biotechnol. J. 2009, 4, 98-107.

54. Plouffe, P.; Macchi, A.; Roberge, D. M. Org. Process Res. Dev. 2014,

$18,1286-1294$

55. Itabaiana Jr., I.; De Mariz E Miranda, L. S.; De Souza, R. O. M. A. J. Mol.

Catal. B, Enzym. 2013, 85-86, 1-9.

56. Rao, N. N.; Lütz, S.; Würges, K.; Minör, D. Org. Process Res. Dev.

2009, 13, 607-616.

57. Anderson, N. Org. Process Res. Dev. 2012, 16, 852-869.

58. DiCosimo, R.; McAuliffe, J.; Poulose, A. J.; Bohlmann, G. Chem. Soc. Rev.

2013, 42, 6437-6474.

59. Bolivar, J. M.; Wiesbauer, J.; Nidetzky, B. Trends Biotechnol. 2011, 29, 333-342.

60. Ziogas, A.; Kolb, G.; Kost, H. J.; Hessel, V. Chemie-Ingenieur-Technik 2011, 83, 465-478.

61. Maquieira, A.; Casamayor, F.; Puchades, R. Anal. Chim. Acta 1993, 283, 401-407.

62. Shimada, K.; Shimoda, T.; Kokusen, H.; Nakano, S. Talanta 2005, 66, $80-85$.

63. Timmer, B. H.; van Delft, K. M.; Olthuis, W.; Bergveld, P.; van den Berg, A.

Sens. Actuators, B 2003, 91, 342-346.

64. Wootton, R. C. R.; DeMello, A. J. Chem. Commun. 2004, No. 3, 266-267.

65. Park, C. P.; Kim, D.-P. J. Am. Chem. Soc. 2010, 132, 10102-10106.

66. Liu, X.; Jensen, K. F. Green Chem. 2013, 15, 1538-1541.

67. Hartman, R. L.; Sahoo, H. R.; Yen, B. C.; Jensen, K. F. Lab Chip 2009,

9, 1843-1849.

68. Salmon, J.-B.; Leng, J. J. Appl. Phys. 2010, 107, 084905

69. Cooney, D.; Hamel, E.; Cohen, M.; Kang, G. J.; Dalal, M.; Marquez, V.

Biochim. Biophys. Acta 1987, 916, 89-93.

70. Tang, Z.; Kang, J. Anal. Chem. 2006, 78, 2514-2520.

71. Gottschlich, N.; Culbertson, C. T.; McKnight, T. E.; Jacobson, S. C.;

Ramsey, M. J. Chromatogr B 2000, 745, 243-249.

72. Huynh, B. H.; Fogarty, B. A.; Nandi, P.; Lunte, S. M. J. Pharm. Biomed.

Anal. 2006, 42, 529-534.

73. Sanders, G. H. W.; Manz, A. Trends Anal. Chem. 2000, 19, 364-378.

74. Khandurina, J.; Guttman, A. J. Chromatogr. A 2002, 943, 159-183.

75. Figeys, D.; Pinto, D. Electrophoresis 2001, 22, 208-216.

76. Guihen, E. Electrophoresis 2014, 35, 138-146.

77. Robins, I.; Shaw, J.; Miller, B.; Turner, C.; Harper, M. In Proc. of the 1st Int. Conf. on Microreaction Technology; 1997; p. 35.
78. Kirschneck, D.; Wojik, A.; Marr, R. In 7th Internatinoal Conference on Microreaction Technology; 2003; pp. 38-40.

79. Li, X.; Xue, A.; Chen, H.; Li, S. J. Chromatogr. A 2013, 1280, 9-15.

80. Ekström, S.; Malmström, J.; Wallman, L.; Löfgren, M.; Nilsson, J.;

Laurell, T.; Marko-Varga, G. Proteomics 2002, 2, 413-421.

81. Yan, Y.; Chen, X.; Hu, S.; Bai, X. J. Chromatogr. A 2014, 1368, 1-17.

82. Cervera-Padrell, A. E.; Morthensen, S. T.; Lewandowski, D. J.; Skovby, T.;

Kiil, S.; Gernaey, K. V. Org. Process Res. Dev. 2012, 16, 888-900.

83. Li, P.; Moore, J. S.; Jensen, K. F. Chem CatChem 2013, 5, 1729-1733. 84. Hereijgers, J.; Callewaert, M.; Lin, X.; Verelst, H.; Breugelmans, T.;

Ottevaere, H.; Desmet, G.; De Malsche, W. J. Memb. Sci. 2013, 436, 154-162.

85. Cai, Z.-X.; Fang, Q.; Chen, H.-W.; Fang, Z.-L. Anal. Chim. Acta 2006,

$556,151-156$

86. Bechtold, M.; Makart, S.; Heinemann, M.; Panke, S. J. Biotechnol.

2006, 124, 146-162.

87. Shieh, M. T.; Barker, P. E. J. Chem. Technol. Biotechnol. 1996, 66, 265-278.

88. Lai, S. M.; Ng, C. P.; Martin-Aranda, R.; Yeung, K. L. Microporous

Mesoporous Mater. 2003, 66, 239-252.

89. Yamamoto, S.; Hanaoka, T.; Hamakawa, S.; Sato, K.; Mizukami, F. Catal. Today 2006, 118, 2-6.

90. Du, L.; Li, J.; Li, W.; Li, Y.; Li, T.; Xiao, D. Food Res. Int. 2014, 57, $61-70$.

91. Kenig, E. Y.; Su, Y.; Lautenschleger, A.; Chasanis, P.; Grünewald, M. Sep Purif. Technol. 2013, 120, 245-264.

92. McMullen, J. P.; Jensen, K. F. Annu. Rev. Anal. Chem. 2010, 3, 19-42. 93. Luttmann, R.; Bracewell, D. G.; Cornelissen, G.; Gernaey, K. V.; Glassey, J.;

Hass, V. C.; Kaiser, C.; Preusse, C.; Striedner, G.; Mandenius, C.-F. Biotechnol. J.

2012, 7, 1040-1048.

94. Zhao, D.; Ding, K. ACS Catal. 2013, 3, 928-944.

95. Baxendale, I. R. J. Chem. Technol. Biotechnol. 2013, 88, 519-552.

96. Hessel, V.; Kralisch, D.; Kockmann, N.; Noël, T.; Wang, Q. ChemSusChem

2013, 6, 746-789.

97. Whitesides, G. M. Nature 2006, 442, 368-373.

98. McQuade, D. T.; Seeberger, P. H. J. Org. Chem. 2013, 78, 6384-6389.

99. Wegner, J.; Ceylan, S.; Kirschning, A. Adv. Synth. Catal. 2012, 354, 17-57.

100. Žnidaršič-Plazl, P.; Plazl, I. Process Biochem. 2009, 44, 1115-1121.

101. Blow, N. Nat. Methods 2009, 6, 683-686.

102. Bieringer, T.; Buchholz, S.; Kockmann, N. Chem. Eng. Technol. 2013,

36, 900-910.

103. Jensen, K. F.; Reizman, B. J.; Newman, S. G. Lab Chip 2014, 14, 3206-3212.

104. Fagaschewski, J.; Bohne, S.; Kaufhold, D.; Müller, J.; Hilterhaus, L. Green Process Synth. 2012, 1, 337-344.

105. Pohar, A.; Žnidaršič-Plazl, P.; Plazl, I. Chem. Eng. J. 2012, 189-190, 376-382.

106. Saric, M.; van der Wielen, L. A. M.; Straathof, A. J. J. Chem. Eng. Sci. 2011, 66, 510-518.

107. Lundemo, M. T.; Woodley, J. M. Appl. Microbiol. Biotechnol. 2015, 99 , 2465-2483.

108. Zehentgruber, D.; Hannemann, F.; Bleif, S.; Bernhardt, R.; Lütz, S. ChemBioChem 2010, 11, 713-721.

109. Ramesh, H.; Woodley, J. M. J. Mol. Catal. B, Enzym. 2014, 106, 124-131. 110. Hilker, I.; Gutiérrez, M. C.; Furstoss, R.; Ward, J.; Wohlgemuth, R.; Alphand, V. Nat. Protoc. 2008, 3, 546-554.

111. Lopez, J. L.; Matson, S. L. J. Memb. Sci. 1997, 125, 189-211.

112. Solano, D. M.; Hoyos, P.; Hernáiz, M. J.; Alcántara, A. R.; Sánchez-

Montero, J. M. Bioresour. Technol. 2012, 115, 196-207.

113. Malik, M. S.; Park, E. S.; Shin, J. S. Appl. Microbiol. Biotechnol. 2012 ,

94, 1163-1171. 